(2) Open Access Full Text Article

ORIGINALRESEARCH

\title{
Assessment of Isoniazid Preventive Therapy Outcome Among People Living with HIV in a Referral Hospital, Northeast Ethiopia
}

This article was published in the following Dove Press journal: Integrated Pharmacy Research and Practice

\author{
Yohannes Mengesha (1D) \\ Muhammed Ahmed ${ }^{2}$ \\ 'Department of Pharmacy, Pharmaceutics \\ Unit, Wollo University, College of \\ Medicine and Health Sciences, Dessie, \\ Ethiopia; ${ }^{2}$ Dessie Referral Hospital, \\ Dessie, Ethiopia
}

Background: Tuberculosis is said to be one of the prevalent opportunistic infections and the leading cause of death among people living with human immunodeficiency virus. Although isoniazid preventive therapy (IPT) is thought to reduce the incidence of TB in HIV patients, its implementation has faced many obstacles. This study was concerned with the assessment of the outcome of IPT among people living with HIV who were on follow-up at Dessie referral Hospital (DRH), Northeast, Ethiopia.

Methods: A retrospective study of medical records of 220 patients, who were enrolled at Dessie Referral Hospital from January 10/2016 to December 11/2018, were conducted from March 23/2019 to April 6/2019. A systematic random sampling method was used to select the samples for the study, and a data abstraction format was used to capture the data. All data were entered, cleared and analyzed using SPSS version 21. Chi-square test was used to identify the association of outcome between the two IPT groups, and P-value $<0.05$ was considered as statistical significance.

Results: The total TB prevalence in this study was $25(11.36 \%)$. The occurrence of TB in the IPT group was $9(4.09 \%)$ and $16(7.27 \%)$ for the non-IPT group but not statistically significant $(\mathrm{p}=0.137)$. From the study, about $40.9 \%$ of patients developed opportunistic infections. Of these, $62.81 \%$ and $37.18 \%$ of opportunistic infections were developed among patients in the non-IPT and the IPT groups, respectively $(\mathrm{p}=0.002)$, which were statistically significant, and the IPT completion rate was $61.81 \%$.

Conclusion: Although the current study showed that the IPT had not significantly reduced the prevalence of TB between IPT and the non-IPT group, the IPT has shown to significantly reduce the prevalence of opportunistic infections.

Keywords: ART patients, IPT prophylaxis, DRH, TB
Correspondence: Yohannes Mengesha Email joymengesha@gmail.com

\section{Background}

Human Immunodeficiency Virus (HIV) continues to be a major global public health issue. In 2018 an estimated 37.9 million people were living with HIV (including 1.7 million children), with a global HIV prevalence of $0.8 \%$ among adults. ${ }^{1}$ According to the world health organization (WHO) African region remains most severely affected, with nearly 1 in every 25 adults (3.9\%) living with HIV and accounting for more than two-thirds of the people living with HIV worldwide. ${ }^{2}$ The progress of HIV is exacerbated by the presence of opportunistic infections (OIs) like Tuberculosis (TB), malaria, and others. People living with HIV who are on $\mathrm{ART}$ are at high risk of developing $\mathrm{TB}^{3}$ 
$\mathrm{TB}$ is the second most common cause of death from infectious diseases worldwide next to HIV. ${ }^{4}$ TB latently affected about one -third of the world's population. ${ }^{5}$ Individuals with associated immunosuppression, mostly due to HIV infection are highly susceptible to TB infection. About $10 \%$ of tuberculosis-infected individuals will develop overt clinical disease ${ }^{6}$ and about half of them develop the disease more than two years after infection. ${ }^{7}$ Immunocompetent individuals have a risk of $5-10 \%$ of developing active TB this number is increased to $5-15 \%$ annually in HIV-infected individuals during their lifetime. ${ }^{8}$

Ethiopia is one of the most affected countries globally with TB, TB/HIV, and multi-drug resistant (MDR)-TB. In Ethiopia, the prevalence of HIV among adults was $1 \%$ (CI: $0.7 \%$ to $1.4 \%$ ) and the incidence rate of TB was $151 / 100000$ in $2018 .{ }^{9}$ $\mathrm{TB}$ is one of the most common OIs among PLHIV in Ethiopia and $10 \%$ of those individuals with HIV will develop TB. ${ }^{10}$ Besides the early initiation of ART, starting IPT will reduce the incidence of TB in HIV patients. According to the WHO report, using IPT reduces the incidence of TB by about $33 \%{ }^{11}$ Although Ethiopia started implementing IPT in 2007, its implementation has faced many obstacles including poor patient adherence, fear of side effects, and lack of commitment of health workers and the others. ${ }^{12}$ Therefore, the purpose of this study is to assess the outcome of IPT including the prevalence of TB, other opportunistic infections.

\section{Methods}

\section{Study Setting and Period}

A retrospective study of medical records of 220 patients who were enrolled at Dessie Referral Hospital from January 10/ 2016 to December 11/2018, was conducted from March 23/ 2019 to April 6/2019. The study was conducted at Dessie Referral Hospital ART clinic, which is found in Dessie town, northeast Ethiopia. Dessie is a town which is located $401 \mathrm{~km}$ away from Addis Ababa, the capital city of Ethiopia. The hospital serves a population of more than two million people and it is the only teaching hospital in the town and has many major wards, namely medical, ambulatory, psychiatric, surgical, pediatrics, and Gynecology/Obstetrics, pharmacy, and ART. ART clinic of the hospital gives services such as; assessment of the clinical status of the patients, counseling and adherence support, CD4, and viral load test.

\section{Data Collection}

The study was based on secondary data taken from ART follow-up form and registration book at the DRH ART clinic. Data abstraction format containing the variables socio-demographic factor (Age, Sex, Religion, Educational status ....), clinical parameters (clinical WHO stage, $\mathrm{CD}_{4}{ }^{+}$ cells count, weight, OI treatment initiation, other lab parameters) and IPT information were used to collect data.

\section{Sample Size and Sampling Procedure}

The required sample size for the study was determined by using single population proportion formula with the assumptions of the prevalence of TB infection which is $68 \%$ and $38 \%$ in HIV co-infected individuals and non-HIV infected individuals respectively ${ }^{13}$ and the constants $95 \%$ confidence interval, and 5\% marginal error. Two hundred and twenty individuals were determined to be included for this study using a 1:1 ratio of both groups. Systematic random sampling was used to select the study participants both in the Non-IPT and the IPT independently. Patients who had completed six months of isoniazid prophylaxis were considered exposed (IPT group) and patients who had never been offered IPT were considered unexposed (non-IPT). Patients who were on ART follow up, age 18 and above, and who were free of active TB were included in the study while patients who had incomplete medical, clinical, laboratory data records, and those patients who were transferred were excluded from the study.

\section{Ethical Consideration}

An Official letter of cooperation was obtained from the department of pharmacy, Wollo University before the commencement of the study. This letter was submitted to the administrative officials of the hospital to conduct the study in Dessie Referral Hospital. Ethical clearance was issued from the College of Medicine and Health Science Ethical Committee, Wollo University (CMHS/225/022/19). The purpose of the study was disclosed to the relevant officials in the hospital. Due to the retrospective nature of the study, the consent of the patient was waived by the committee. The confidentiality of information was secured and no personal identifier was included in the data abstraction format. This study was conducted under the ethical guidelines of the Declaration of Helsinki.

\section{Data Analysis}

All data were entered, cleared and analyzed using Statistical Package for the Social Sciences (SPSS) version 21 (IBM Corporation, Armonk, NY, USA). Chi-square test was used to identify the association of outcome with the two groups of Isoniazid prophylaxis therapy and P-value $<0.05$ was considered as statistical significance. 


\section{Data Quality Control}

To ensure the quality of data, data collection instruments were tested on $10 \%$ of the total sample size from other hospitals, data abstraction format was checked for its consistency and completeness. Abstraction format was extensively piloted before implementation and a team of data collectors were trained before data collection.

\section{Results}

\section{Socio-Demographic Characteristic Data}

Two hundred twenty study participants were involved from both IPT and NIPT groups, grouped based on their exposure status to INH, 110 each. Ninety-three $(43.2 \%)$ were male and one hundred twenty-seven $(57.7 \%)$ were female. One hundred and ten $(50 \%)$ of the participants were aged between 25 and 34 years. The mean (SD) and the median age of the study participants calculated were $27.67 \pm 8.81$, and 28 , respectively. From the total study participants, 129 (58.6\%) was Orthodox by religion followed by Muslim 52 (23.6\%). Forty-nine $(22.27 \%)$ study participants were illiterate while, the remaining $171(77.72 \%)$ of the participants were educated up to a primary level. About 55.4\% (122) of the study participants were married (Table 1).

\section{Enrollment Date}

An Overall larger proportion of this retrospective cohort study participant was enrolled from January 1/2016 to 2017 accounted for 102 (43.36\%), followed by 67 (30.45\%) of Jan $1 / 2018$ to December $1 / 2019$ and finally from 2017 to 2018 was 51 (23.18\%). The overall participant of the exposed group is increasing as compared to the unexposed group during follow up, but not statistically significant $(\mathrm{p}=0.656)$.

\section{Baseline Clinical, Immunological and Laboratory Values}

At baseline, the majority of the patients in this cohort study, $185(84.09 \%)$, had BMI between 18.5 and $25 \mathrm{~kg} / \mathrm{m}^{2}$ and a CD4 count of $<350 \mathrm{cell} / \mathrm{mm}^{3}$ in $112(50.90 \%)$ participants. The leading percentage of study participants were on WHO clinical stage II (36.81\%) and work functional status (90.90\%). Most of the included participants 138 (62.72\%) had a Hgb count greater than $12 \mathrm{mg} / \mathrm{dl}$, and 91 (41.36\%) had a baseline weight of 50-59 for the entire cohort (Table 2).

\section{Drug-Related Information}

Almost the entire participant in this cohort study was taking ART medications of which the majority of them, 187 (85\%) were on $\mathrm{TDF} / 3 \mathrm{TC} / \mathrm{EFV}$ based regimen Whereas in the case of prophylaxis, 157 (71.36\%) received

Table I Socio-Demographic Variables of Patients on IPT Among ART Patients in DRH, from January I0/20 I6 to December I I/20 I8

\begin{tabular}{|c|c|c|c|c|}
\hline Variables & Category & IPT Group No. (\%) & Non-IPT Group No. (\%) & p-value \\
\hline \multirow[t]{2}{*}{ Sex } & Male & $45(40.9 \%)$ & $48(43.63 \%)$ & 0.682 \\
\hline & Female & $65(59.0 \%)$ & $62(56.36 \%)$ & \\
\hline \multirow[t]{4}{*}{ Age } & $0-14$ & $8(7.27 \%)$ & $7(6.36 \%)$ & $0.94 I$ \\
\hline & $15-24$ & $23(20.90 \%)$ & $23(20.90 \%)$ & \\
\hline & $25-34$ & $53(48.18 \%)$ & $57(51.81 \%)$ & \\
\hline & $>35$ & $26(23.63 \%)$ & $23(20.90 \%)$ & \\
\hline \multirow[t]{3}{*}{ Religion } & Orthodox & $61(55.45 \%)$ & $68(61.81 \%)$ & 0.150 \\
\hline & Muslim & $32(29.09 \%)$ & $20(18.18 \%)$ & \\
\hline & Protestant & $17(\mid 5.45 \%)$ & $22(20 \%)$ & \\
\hline \multirow[t]{4}{*}{ Marital status } & Married & $64(58.18 \%)$ & $58(52.72 \%)$ & 0.833 \\
\hline & Single & $31(28.18 \%)$ & $33(30 \%)$ & \\
\hline & Divorced & $13(\mid 1.81 \%)$ & $16(14.54 \%)$ & \\
\hline & Widowed & $2(1.81 \%)$ & $3(2.72 \%)$ & \\
\hline \multirow[t]{4}{*}{ Educational level } & Cannot read and write & $27(24.54 \%)$ & $22(20 \%)$ & 0.291 \\
\hline & Primary & $56(50.90 \%)$ & $50(45.45 \%)$ & \\
\hline & Secondary & $19(17.27 \%)$ & $22(20 \%)$ & \\
\hline & College & $8(7.27 \%)$ & $16(14.54 \%)$ & \\
\hline
\end{tabular}


Table 2 Clinical Variables of Patients on IPT Among ART Patients in DRH, from January 10/20I6 to December II/20I8

\begin{tabular}{|c|c|c|c|c|}
\hline Variables Group & Category & IPT Group No. (\%) & Non-IPT No. (\%) & P-value \\
\hline WHO stage & $\begin{array}{l}\text { One } \\
\text { Two } \\
\text { Three } \\
\text { Four }\end{array}$ & $\begin{array}{l}35(31.81 \%) \\
33(30 \%) \\
42(38.18 \%)\end{array}$ & $\begin{array}{l}20(18.18 \%) \\
48(43.63 \%) \\
38(34.54 \%) \\
4(3.63)\end{array}$ & 0.011 \\
\hline CD4 count (cell/mm³) & $\begin{array}{l}\leq 350 \\
350-499 \\
\geq 500\end{array}$ & $\begin{array}{l}56(50.90 \%) \\
20(18.18 \%) \\
34(30.90 \%)\end{array}$ & $\begin{array}{l}56(50.90 \%) \\
22(20 \%) \\
32(29.09 \%)\end{array}$ & 0.925 \\
\hline BMI $\left(\mathrm{Kg} / \mathrm{m}^{2}\right)$ & $\begin{array}{l}\leq 18 \\
18-25 \\
\geq 25\end{array}$ & $\begin{array}{l}19(\mid 7.27 \%) \\
90(81.81 \%) \\
I(0.90 \%)\end{array}$ & $\begin{array}{l}13(1 \mid .81 \%) \\
95(86.36 \%) \\
2(1.81 \%)\end{array}$ & 0.346 \\
\hline $\mathrm{Hgb}(\mathrm{mg} / \mathrm{dl})$ & $\begin{array}{l}\leq 12 \\
\geq 12\end{array}$ & $\begin{array}{l}35(31.81 \%) \\
75(68.18 \%)\end{array}$ & $\begin{array}{l}47(42.72 \%) \\
63(57.27 \%)\end{array}$ & 0.124 \\
\hline Functional working status & $\begin{array}{l}\text { Working } \\
\text { Ambulatory } \\
\text { Bedridden }\end{array}$ & $\begin{array}{l}I 0 I(91.81 \%) \\
9(8.18 \%) \\
0(0)\end{array}$ & $\begin{array}{l}99(90 \%) \\
10(9.90 \%) \\
1(0.90 \%)\end{array}$ & 0.537 \\
\hline Viral load & $\begin{array}{l}\leq 50 \\
50-500 \\
\geq 500\end{array}$ & $\begin{array}{l}4(22.22 \%) \\
\mathrm{I}(5.55 \%) \\
2(1 \mathrm{I} .1 \mathrm{I} \%)\end{array}$ & $\begin{array}{l}0(0) \\
4(22.22 \%) \\
7(38.88 \%)\end{array}$ & 0.245 \\
\hline
\end{tabular}

CPT, 47 (21.4\%) study participants and $10(5.5 \%)$ were also using anti-pain and antifungal medication, respectively. Another medication that is mostly used by the entire cohort was plumpy net 22 (10\%), Amoxicillin 17 (7.7\%), and $14(6.4 \%)$ pyridoxine in the exposed group only, respectively (Table 3 ).

\section{Outcome of IPT}

The prevalence of new TB cases in this study was 25 $(11.36 \%)$. The prevalence of TB in the IPT group was 9 $(4.09 \%)$ and $16(7.27 \%)$ for non-IPT group which was not statistically significant $(\mathrm{p}=0.137)$ CI $(0.202-0.101)$. The method of diagnosis of the cohort was smear AFP

Table 3 Drug-Related Information Among the ART Patients in the ART Clinic of DRH from January I0/ 2016 to December $11 / 2018$

\begin{tabular}{|c|c|c|c|c|}
\hline Variables & Category & IPT Group No. (\%) & Non-IPT Group No. (\%) & P-value \\
\hline ART regimen & $\begin{array}{l}\text { (TDF/3TC/EFV) } \\
\text { (TDF/3TC/NVP) } \\
\text { (AZT/3TC/EFV) } \\
\text { (AZT/3TC/NVP) } \\
\text { (ABC/3TC/EFV) } \\
\text { (ABC/3TC/NVP) }\end{array}$ & $\begin{array}{l}98(89.09 \%) \\
I(0.90 \%) \\
0(0) \\
5(4.54 \%) \\
I(0.90 \%) \\
5(4.54 \%)\end{array}$ & $\begin{array}{l}89(80.90 \%) \\
7(6.36 \%) \\
1(0.90 \%) \\
10(9.90 \%) \\
1(0.90 \%) \\
2(1.81 \%)\end{array}$ & 0.114 \\
\hline CPT & $\begin{array}{l}\text { Fluconazole } \\
\text { Grisseofulvin } \\
\text { Ketoconazole } \\
\text { Diclofenac } \\
\text { Ibuprofen } \\
\text { Paracetamol } \\
\text { Albendazole } \\
\text { Praziquantel }\end{array}$ & $\begin{array}{l}78(72.2 \%) \\
4(3.7 \%) \\
I(0.9 \%) \\
0(0) \\
8(7.4 \%) \\
2(1.8 \%) \\
9(8.3 \%) \\
5(4.6 \%) \\
I(0.9 \%)\end{array}$ & $\begin{array}{l}79(69.9 \%) \\
3(2.65 \%) \\
1(0.9 \%) \\
1(0.9 \%) \\
12(10.6 \%) \\
1(0.9 \%) \\
12(8.8 \%) \\
4(3.5 \%) \\
0(0)\end{array}$ & $\begin{array}{l}0.376 \\
0.568 \\
0.617\end{array}$ \\
\hline
\end{tabular}


Table 4 The Outcome of IPT Among ART Patients in DRH from January 10/2016 to December II/2018

\begin{tabular}{|l|l|l|l|l|}
\hline Variables & Category & $\begin{array}{l}\text { IPT } \\
\text { Group }\end{array}$ & $\begin{array}{l}\text { Non-IPT } \\
\text { Group }\end{array}$ & p-value \\
\hline TB status & $\begin{array}{l}\text { Positive } \\
\text { Negative }\end{array}$ & $\begin{array}{l}9(4.09 \%) \\
101(45.9)\end{array}$ & $\begin{array}{l}16(7.27 \%) \\
94(42.72)\end{array}$ & 0.137 \\
\hline $\begin{array}{l}\text { Opportunistic } \\
\text { infections }\end{array}$ & Yes & $56(61.8 \%)$ & $34(15.5 \%)$ & 0.002 \\
\hline CD4 count & No & $54(38.2 \%)$ & $76(34.5)$ & \\
& 6 months & 408.8 & 407.6 & 0.486 \\
& 12 months & 590.2 & 502.1 & 0.307 \\
& 511.9 & 0.265 \\
\hline
\end{tabular}

in $24(96 \%)$, which was positive in $18(72 \%)$ of cases (Table 4).

The mean CD4 count of participants at baseline, six, and 12 months were analyzed and compared between the two groups. The overall mean CD4 improvement was greater among exposed $538.37 \mathrm{cell} / \mathrm{mm}^{3}$ than unexposed 502.10 cell $/ \mathrm{mm}^{3}$ after six months of follow up but not statistically significant ( $\mathrm{p}=0.307$ ) (Table 4).

From the study cohort, about $40.9 \%$ of patients developed opportunistic infections. The Prevalent type of OIs was community-acquired pneumonia $(11.8 \%)$, oral candidiasis $(6.81 \%)$, and Herpes zoster (5.9\%). The majority of those OI was developed by the patients in the Non-IPT group, $62.81 \%$, than the IPT group $(37.18 \%)$ which was statistically significant $(\mathrm{p}=0.002)$ (Table 4$)$.

\section{Completion Rate of IPT}

This retrospective cohort study shows that among 220 HIV positive patients 110, was taking isoniazid prophylaxis therapy. From this, $68(61.81 \%)$ completed their prophylaxis who took for at least 6 months. The average duration of isoniazid prophylaxis was $12.80 \pm 6.69$ and range of (6-37) but $42(38.18 \%)$ did not finish their prophylaxis they took about $4.17 \pm 1.27$ months and range of (1-5) months.

\section{Discussion}

According to the $\mathrm{WHO}$, Isoniazid prophylaxis taken for about 6 to 12 months reduces TB incidences by about 33\% among people living with HIV. ${ }^{14}$ The overall outcome of IPT in this study in three consecutive years shows that there was 25 overall prevalence of tuberculosis, of this 9 $(4.4 \%)$ was from IPT, and $16(7.7 \%)$ was from the non-IPT group, respectively. Greater TB prevalence was observed on those patients without prophylaxis than the patients on IPT but not statistically significant $(p=0.137)$. This incidence value in this study was in agreement with a study done in Jimma University medical center which shows that 49 individuals were observed to show new TB cases, with an incidence of $13(4.42 \%)$, in the IPT group and $36(12.24 \%)$ in the non-IPT group. ${ }^{15}$ Even if the total sample size is small, the overall outcome of IPT in this study is better than a study which is done in Arbaminch hospital, $12(8.7 \%)$ of the IPT group, and about 37 $(27.8 \%)$ in the non-IPT had acquired TB infection. ${ }^{13}$ But, this result was greater than the study done Rio de Janeiro, Brazil on 29 public clinics, by which $1.4 \%$ of the IPT and $3.8 \%$ from the non-IPT were diagnosed with TB. ${ }^{14}$ This is maybe attributed to the time in which the study was done and completion rate differences.

Increasing the CD4 count level among the two groups of study subjects was compared over a one-year follow-up. The average CD4 cell count was not statistically significant for both groups at the baseline But the average CD4 count showed an increment in IPT group and non-IPT group ART patients after 6 months $(p=0.307)$. For the consecutive level of CD4 cell count at 12 months, there was not a significant difference between the two groups of the unexposed groups $(\mathrm{p}=0.265)$. The immune response at 12 months was due to the mean differences between the two groups at baseline. Overall, there was an elevation in CD4 count in the Exposed group as compared to in unexposed group after treatment. ART may be the possible reason for the reduction of TB. ${ }^{16}$ ART aids in minimization of viral load and recovery of the immune status of the patients that in turn reduces the development of opportunistic diseases. But, the number of TB coinfected participants was greater among the non-IPT group than the IPT group. The results of this study concerning mean CD4 count recovery was supported by a study conducted in Arbaminch hospital but without significant differences $(P=0.2)$ after 6 months. $^{13}$

The prevalence of opportunistic infections in this study was determined to be $40.9 \%$. This value was lower than a study done on other parts of Ethiopia; which were $(52.4 \%)^{17}$ and $(48 \%)^{18}$ in Bahirdar and Eastern Ethiopia, respectively, but higher than a study done in Addis Ababa $(33.6 \%) .{ }^{19}$ The most Prevalent type of OIs was community-acquired pneumonia (11.8\%), Majority of those OI was developed by the patients in the non-IPT group, $62.18 \%$, than the IPT group $(37.18 \%)$ which was statistically significant $(\mathrm{p}=0.002)$.

In this study the completion rate of IPT determined for about six months was $68(61.81 \%)$. This completion rate 
value is less than the study which is done in, Swaziland, ${ }^{20}$ South Africa, ${ }^{21}$ and Addis Ababa $^{19}$ Cambodia $^{22}$ reported as $78 \%, 89.4 \%, 69 \%$, and $77.1 \%$, respectively, but had a better outcome in a study which is done in south Ethiopia (50.9\%). ${ }^{16}$ The reason for non-completion might be the development of drug toxicity like hepatotoxicity and rash and refusal and unable to finish the regimen by the patients and others. The current finding will empower healthcare workers in further implementation of IPT for the reduction of new TB cases and other opportunistic infections in people living with HIV.

\section{Limitation}

This study has limitations: Since the study is retrospective that involved the analysis of secondary data. We were unable to control for some of the confounding variables like other nutritional status indicators other than BMI.

\section{Conclusion}

Although the current study showed that the IPT had not significantly reduced the prevalence of TB between IPT and the non-IPT group, the IPT has shown to significantly reduce the prevalence of opportunistic infections.

\section{Abbreviation}

ART, anti-retroviral therapy; DRH, Dessie Referal Hospital; HIV, human immunodeficiency virus; IPT, isoniazid prophylaxis therapy; TB, tuberculosis; WHO, World Health Organization.

\section{Data Sharing Statement}

Most of the data available were shared on the document. However, the datasets used and analyzed are available from the author on any request.

\section{Acknowledgment}

The authors like to acknowledge the Dessie Referral Hospital staff and the study participants for their cooperation throughout the data collection.

\section{Author Contributions}

All authors made a significant contribution to the work reported, whether that is in the conception, study design, execution, acquisition of data, analysis and interpretation, or in all these areas; took part in drafting, revising or critically reviewing the article; gave final approval of the version to be published; have agreed on the journal to which the article has been submitted; and agree to be accountable for all aspects of the work.

\section{Funding}

There is no funding to report.

\section{Disclosure}

The authors would like to report they have no conflicts of interest in this study.

\section{References}

1. UNAIDS. Fact sheet-latest statistics on the status of the AIDS epidemic; 2016. 2017. Available from: https://www.unaids.org/en/ resources/fact-sheet. Accessed August 18, 2020.

2. HIV/AIDS JUNPo. Global report: UNAIDS report on the global AIDS epidemic 2010: unaids. 2013. Available from: https://www.unaids.org/ globalreport/Global report.htm. Accessed January 14, 2020.

3. Lawn SD, Harries AD, Anglaret X, Myer L, Wood R. Early mortality among adults accessing antiretroviral treatment programs in sub-Saharan Africa. AIDS. 2008;22:1897-1908. doi:10.1097/QAD. 0b013e32830007cd

4. Mitku AA, Dessie ZG, Muluneh EK, Workie DL. Prevalence and associated factors of TB/HIV co-infection among HIV Infected patients in Amhara region, Ethiopia. Afr Health Sci. 2016;16 (2):588-595. doi:10.4314/ahs.v16i2.29

5. Manabe YC, Bishai WR. Latent Mycobacterium tuberculosis - persistence, patience, and winning by waiting. Nat Med. 2000;6: 1327-1329. doi:10.1038/82139

6. Selwyn PA, Hartel D, Lewis VA, et al. A prospective study of the risk of tuberculosis among intravenous drug users with human immunodeficiency virus infection. $N$ Engl $J$ Med. 1989;320:545-550. doi:10.1056/NEJM198903023200901

7. Lillebaek T, Dirksen A, Vynnycky E, Baess I, Thomsen V, Andersen Å. Stability of DNA patterns and evidence of Mycobacterium tuberculosis reactivation occurring decades after the initial infection. $J$ Infect Dis. 2003;188:1032-1039. doi:10.1086/378240

8. Aaron L, Saadoun D, Calatroni I, et al. Tuberculosis in HIV-infected patients: a comprehensive review. Clin Microbiol Infect. 2004;10:388-398. doi:10.1111/j.1469-0691.2004.00758.x

9. UNAIDS. UNAIDS data. 2019. Available from: https://www.unaids.org/ en/resources/documents/2019/2019-UNAIDS-data. Accessed August 18, 2020.

10. WHO. Global tuberculosis report. 2017. Available from: https://relief web.int/report/world/global-tuberculosis-report-2017 on page 21 . Accessed June 20, 2020.

11. WHO. Global tuberculosis report. 2015. Available from: https://relief web.int/report/world/global-tuberculosis-report-2015. Accessed June $12,2020$.

12. FMOH. Implementation guideline for TB/HIV collaborative activities in Ethiopia. Addis Ababa: Federal Ministry of Health; 2008.

13. Ashenafi A, Tsegaye Y. Assessment of isoniazid preventive therapy in the reduction of tuberculosis among ART patients in Arba Minch Hospital, Ethiopia. Ther Clin Risk Manag. 2017;13:363-365.

14. Golub JE, Saraceni V, Cavalcante SC, et al. The impact of antiretroviral therapy and isoniazid preventive therapy on tuberculosis incidence in HIV-infected patients in Rio de Janeiro, Brazil. AIDS. 2007;21(11):1441-1448. doi:10.1097/QAD.0b013e328216f441

15. Assebe LF, Reda HL, Wubeneh AD, Lerebo WT, Lambert SM. The effect of isoniazid preventive therapy on the incidence of tuberculosis among HIV-infected clients under pre-ART care Jimma, Ethiopia. BMC Public Health. 2015;15:346. 
16. Lawn SD, Wood R, De Cock KM, Kranzer K, Lewis JJ, Churchyard GJ. Antiretroviral and isoniazid preventive therapy in the prevention of HIV-associated tuberculosis in settings with limited health-care resources. Lancet Infect Dis. 2010;10(7):489-498. doi:10.1016/S1473-3099(10)70078-5

17. Abera B, Walle F, Tewabe T, Alem A, Yessin M. ART-naive HIV patients at Feleg-hiwot referral Hospital Northwest, Ethiopia. Ethiop J Heal Dev. 2010;24(1):3-8.

18. Mitiku H, Weldegebreal F, Teklemariam Z. The Magnitude of opportunistic infections and associated factors in HIV-infected adults on antiretroviral therapy in eastern Ethiopia. HIV/AIDS Res Palliat Care. 2015;7:137-144. doi:10.2147/HIV.S79545

19. Mahlet S, Teferi GF, Girmay M, Dawit A. Effectiveness of isoniazid preventative therapy in reducing the incidence of active tuberculosis among people living with HIV/AIDS in public health facilities of Addis Ababa, Ethiopia: a historical cohort study. Infect Dis. 2017;17(5):1-8.

20. Adams LV, Mahlalela N, Talbot EA, et al. High completion rates of isoniazid preventive therapy among persons living with HIV in Swaziland. Int $J$ Tuberc Lung Dis. 2017;21(10):1127-1132. doi:10.5588/ijtld.16.0946

21. Wood R, Bekker L-G. Isoniazid preventive therapy for tuberculosis in South Africa: an assessment of the local evidence base. S Afr Med J. 2014;104(3):174-177. doi:10.7196/SAMJ.7968

22. van Griensven J, Choun K, Chim B, Thai S, Lorent N, Lynen L. Implementation of isoniazid preventive therapy in an HIV clinic in Cambodia: high rates of discontinuation when combined with antiretroviral therapy. Trop Med Int Health. 2015;20(12):1823-1831. doi: $10.1111 /$ tmi. 12609
Integrated Pharmacy Research and Practice

\section{Publish your work in this journal}

Integrated Pharmacy Research and Practice is an international, peerreviewed, open access, online journal, publishing original research, reports, reviews and commentaries on all areas of academic and professional pharmacy practice. This journal aims to represent the academic output of pharmacists and pharmacy practice with particular focus on integrated care. All papers are carefully peer reviewed

\section{Dovepress}

to ensure the highest standards as well as ensuring that we are informing and stimulating pharmaceutical professionals. The manuscript management system is completely online and includes a very quick and fair peer-review system, which is all easy to use. Visit http://www.dovepress.com/testimonials.php to read real quotes from published authors. 